\title{
Identifying the role of Wilms tumor 1 associated protein in cancer prediction using integrative genomic analyses
}

\author{
LI-SHENG WU $^{1 *}$, JIA-YI QIAN ${ }^{2 *}$, MINGHAI WANG $^{3 *}$ and HAIWEI YANG ${ }^{4}$ \\ ${ }^{1}$ Department of General Surgery, Anhui Provincial Hospital, Anhui Medical University, Hefei, Anhui 230001; \\ ${ }^{2}$ Department of Breast Surgery, The First Affiliated Hospital of Nanjing Medical University, Nanjing, Jiangsu 210029; \\ ${ }^{3}$ Department of General Surgery, The First Affiliated Yijishan Hospital of Wannan Medical College, Wuhu, Anhui 241002; \\ ${ }^{4}$ Department of Urology, The First Affiliated Hospital of Nanjing Medical University, Nanjing, Jiangsu 210029, P.R. China
}

Received August 31, 2015; Accepted June 2, 2016

DOI: $10.3892 / \mathrm{mmr} .2016 .5528$

\begin{abstract}
The Wilms tumor suppressor, WT1 was first identified due to its essential role in the normal development of the human genitourinary system. Wilms tumor 1 associated protein (WTAP) was subsequently revealed to interact with WT1 using yeast two-hybrid screening. The present study identified 44 complete WTAP genes in the genomes of vertebrates, including fish, amphibians, birds and mammals. The vertebrate WTAP proteins clustered into the primate, rodent and teleost lineages using phylogenetic tree analysis. From 1,347 available SNPs in the human WTAP gene, 19 were identified to cause missense mutations. WTAP was expressed in bladder, blood, brain, breast, colorectal, esophagus, eye, head and neck, lung, ovarian, prostate, skin and soft tissue cancers. A total of 17 out of 328 microarrays demonstrated an association between WTAP gene expression and cancer prognosis. However, the association between WTAP gene expression and prognosis varied in distinct types of cancer, and even in identical types of cancer from separate microarray databases. By searching the Catalogue of Somatic Mutations in Cancer database, 65 somatic mutations were identified in the human WTAP gene from the cancer tissue samples. These results suggest that the function of WTAP in tumor formation may be multidimensional. Furthermore, signal transducer and activator of transcription 1 , forkhead box protein $\mathrm{O} 1$, interferon
\end{abstract}

Correspondence to: $\mathrm{Dr} \mathrm{Li}-$ Sheng $\mathrm{Wu}$, Department of General Surgery, Anhui Provincial Hospital, Anhui Medical University, 17 Lujiang Road, Hefei, Anhui 230001, P.R. China

E-mail: wlsheng1210@163.com

Dr Haiwei Yang, Department of Urology, The First Affiliated Hospital of Nanjing Medical University, 300 Guangzhou Road, Nanjing, Jiangsu 210029, P.R. China

E-mail: hwyang2002@163.com

\section{${ }^{*}$ Contributed equally}

Key words: comparative genomics, Wilms tumor 1 associated protein, cancer prognosis, meta-analysis regulatory factor 1 , glucocorticoid receptor and peroxisome proliferator-activated receptor $\gamma$ transcription factor binding sites were identified in the upstream (promoter) region of the human WTAP gene, suggesting that these transcription factors may be involved in WTAP functions in tumor formation.

\section{Introduction}

The Wilms tumor suppressor gene WT1 was first identified due to its essential role in the normal development of the human genitourinary system (1). WT1 functions as a transcription factor regulating target gene expression (1). In addition, WT1 was revealed to regulate the expression of genes involved in the Wnt signaling pathway via a genome-wide screening analysis (2).

Wilms tumor 1 associated protein (WTAP) was demonstrated to interact with WT1 using a yeast two-hybrid screening (3). WTAP and WT1 were observed to localize to the nucleoplasm and nuclear speckles, where they were partially co-localized with splicing factors (3). WTAP is the mammalian homolog of the Drosophila gene female-lethal(2) $\mathrm{D}[\mathrm{fl}(2) \mathrm{D}]$, and $\mathrm{fl}(2) \mathrm{D}$ is involved in activating female-specific patterns of alternative splicing of sex-lethal and transformer pre-mRNA $(4,5)$. Previous studies demonstrated that WTAP-null and heterozygous mice succumbed between embryonic day 6.5 and 10.5 , and exhibited marked defects in cell proliferation, which resulted in defects in endoderm and mesoderm formation (6,7). Furthermore, it has been demonstrated in mice that WTAP is required for $\mathrm{G}_{2} / \mathrm{M}$ cell cycle transition by stabilizing the cyclin A2 mRNA and, thus, is vital in early development (6). In addition, WTAP is involved in the function of human spliceosomes (8). Recently, it was demonstrated that WTAP and virilizer are subunits of the N6-methyladenosine methylation complex, which regulates mRNA stability $(9,10)$.

A limited number of studies have been performed on the role of WTAP in tumor genesis. WTAP is overexpressed in cholangiocarcinoma and WTAP expression was observed to correlate with metastasis (11). In addition, WTAP was demonstrated to be overexpressed in glioblastoma, and regulated glioblastoma cell migration and invasion (12). Bansal et al (13) identified WTAP as an oncogenic protein in acute myeloid 
leukemia. Carbonic anhydrase 4, a novel tumor suppressor in colorectal cancer, inhibited the Wnt signaling pathway by targeting the WTAP-WT1-transducin $\beta$-like 1 axis (14). The aim of the present study was to investigate the role of WTAP in tumor formation by identifying novel WTAP genes in vertebrate genomes. The expression of these genes in healthy and tumor tissue samples was determined, and functionally relevant single nucleotide polymorphisms (SNPs) and somatic mutations in WTAP were identified. Conserved transcription factor binding sites within the promoter region of the human WTAP gene were identified. Furthermore, meta-analysis of the prognostic value of WTAP gene expression in various cancers was performed.

\section{Materials and methods}

Identification of novel WTAP genes in vertebrate genomes and transcription factor-binding sites. The DNA and amino acid sequences of novel vertebrate WTAPs were obtained by searching Ensembl genome databases (ensembl.org/index. html) using orthologous and paralogous associations. The prospective WTAP sequences were confirmed using the Basic Local Alignment Search Tool (BLAST; http://blast. ncbi.nlm.nih.gov/Blast.cgi) (15-18). Conserved transcription factor-binding sites in the promoter regions of the human WTAP gene were identified from the SABiosciences' proprietary database, DECODE (Qiagen, Inc., Valencia, CA, USA), which combines text mining with the University of California, Santa Cruz genome browser data (19-21).

Comparative proteomic analyses of WTAP proteins. The amino acid sequences of identified vertebrate WTAPs were aligned using ClustalW (ebi.ac.uk/Tools/msa/). A maximum likelihood (ML) tree of vertebrate WTAPs was constructed using Molecular Evolutionary Genetics Analysis version 5.05 (megasoftware.net/) with the optimal model (Kimura 2-parameter model). The relative support of internal nodes was determined by bootstrap analyses with 1,000 replications for ML reconstructions (22). The program, codeml within the Phylogenetic Analysis by ML version 4.7 software package (abacus.gene.ucl.ac.uk/software/paml.html) was used to investigate whether WTAP proteins were positively selected (23).

Identification of functionally relevant SNPs in the human WTAP gene and somatic mutations in human cancer. The functionally relevant SNPs of the human WTAP gene were extracted from the Ensembl genome databases and the Short Genetic Variations database (ncbi.nlm.nih.gov/snp), as previously described (15-21). The SNPs causing missense mutations were then identified. The somatic mutations of the human WTAP gene in cancer tissues were extracted from the Catalogue of Somatic Mutations in Cancer (COSMIC) database (cancer.sanger.ac.uk/cosmic), which mines somatic mutations in complete cancer genomes (24).

In silico expression analyses of the human WTAP gene. Expression profiles of the human WTAP gene in normal tissues were obtained from the GeneAnnot (genecards. weizmann.ac.il/geneannot/index.shtml) (25) and ArrayExpress (ebi.ac.uk/arrayexpress/) databases (26).
Meta-analysis of the prognostic value of human WTAP gene expression in cancer tissues. The expression of the WTAP gene and the biological association between gene expression and prognosis were determined by inputting human WTAP gene (NP_001257460) into the PrognoScan database (prognoscan.org/) (27).

\section{Results}

Comparative proteomics of WTAP proteins identified in vertebrate genomes. WTAP DNA and protein sequences were collected from the Ensembl genome database and confirmed by BLASTing. Completed WTAP genes were identified in the following genomes: Human, chimpanzee, gibbon, macaque, gorilla, orangutan, olive baboon, vervet monkey, marmoset, tarsier, bush baby, armadillo, sloth, squirrel, elephant, guinea pig, mouse, rat, pika, horse, microbat, ferret, dolphin, dog, pig, sheep, cow, alpaca, chicken, duck, turkey, flycatcher, zebra finch, Chinese softshell turtle, anole lizard, spotted gar, Amazon molly, platyfish, stickleback, tilapia, medaka, cave fish and zebrafish. In the armadillo genome, two WTAP genes were identified. The maximum likelihood method was used to construct the phylogenetic tree of vertebrate WTAPs (Fig. 1). The vertebrate WTAP genes clustered into the primate, rodent and teleost lineages. Furthermore, site-specific analysis for positive selection with six models of codon substitution, M0 (one-ratio), M1a (nearly neutral), M2a (positive selection), M3 (discrete), M7 $(\beta)$, and M8 ( $\beta$ and $\omega)$ were performed in vertebrate, mammalian, bird, reptile and teleost lineages. No sites were identified under positive selection with any models in the various WTAP groups. Therefore, it was concluded that WTAP proteins were under purifying selection (data not shown).

Expression profile of the human WTAP gene. Investigation of available microarray data revealed that the human WTAP gene was predominantly expressed in the following tissues: Bone marrow, whole blood, lymph node, brain, cerebellum, retina, spinal cord, heart, smooth muscle, skeletal muscle, small intestine, colon, adipocyte, kidney, liver, lung, pancreas, thyroid, salivary gland, adrenal gland, skin, ovary, uterus, placenta, prostate and testis. In addition, the human WTAP gene was expressed in the following types of cancer: Bladder, blood, brain, breast, colorectal, esophagus, eye, head and neck, lung, ovarian, prostate, skin and soft tissue.

Comparative genomics on the human WTAP gene. Signal transducer and activator of transcription 1 (STAT1), forkhead box protein $\mathrm{O} 1$ (FOXO1), interferon regulatory factor 1 (IRF1), glucocorticoid receptor and peroxisome proliferator-activated receptor $\gamma$ (PPAR $\gamma$ ) transcription factor binding sites were identified in the upstream (promoter) region of the WTAP gene.

Functionally relevant SNP identification in the human WTAP gene. A total of 1,347 available SNPs were identified in the human WTAP gene. Among these, 19 SNPs were functionally relevant, causing missense mutations (Table I).

Identification of somatic mutations of the WTAP gene in human cancer. By searching the COSMIC database, 
Table I. Functionally relevant SNP identification in the human WTAP gene.

\begin{tabular}{|c|c|c|c|c|}
\hline SNP & Chr 6 position sequence & Sequence & Type & Amino acid \\
\hline rs 1543500 & $159,755,455(+)$ & GGCAG(G/T)GAAAA & Missense & $\mathrm{S}(\mathrm{Ser}) \Rightarrow \mathrm{R}(\mathrm{Arg})$ \\
\hline rs112093927 & $159,753,489(+)$ & GAAGT(A/G)TCGAA & Missense & $\mathrm{C}(\mathrm{Cys}) \Rightarrow \mathrm{Y}(\mathrm{Tyr})$ \\
\hline rs140439442 & $159,755,519(+)$ & AGAAA(A/G)CAGTG & Missense & $\mathrm{A}(\mathrm{Ala}) \Rightarrow \mathrm{T}(\mathrm{Thr})$ \\
\hline rs146208471 & $159,755,499(+)$ & CAGTC(A/G)TGACC & Missense & $\mathrm{H}(\mathrm{His}) \Rightarrow \mathrm{R}(\mathrm{Arg})$ \\
\hline rs144625269 & $159,755,303(+)$ & ACAGG(A/G)AGGGC & Missense & $\mathrm{E}$ (Glu) $\Rightarrow \mathrm{K}$ (Lys) \\
\hline rs148080007 & $159,739,015(+)$ & CTTCA(A/G)AGTTA & Missense & $\mathrm{K}$ (Lys) $\Rightarrow \mathrm{R}(\mathrm{Arg})$ \\
\hline rs149103382 & $159,755,447(+)$ & CTCCC(A/G)CGGGC & Missense & $\mathrm{T}(\mathrm{Thr}) \Rightarrow \mathrm{A}(\mathrm{Ala})$ \\
\hline rs150215853 & $159,743,764(+)$ & $\mathrm{AGCAA}(\mathrm{C} / \mathrm{G}) \mathrm{CAAGG}$ & Missense & $\mathrm{T}(\mathrm{Thr}) \Rightarrow \mathrm{S}$ (Ser) \\
\hline rs187127278 & $159,755,555(+)$ & GTTCC $(\mathrm{C} / \mathrm{T}) \mathrm{GCCAC}$ & Missense & $\mathrm{R}(\mathrm{Arg}) \Rightarrow \mathrm{C}(\mathrm{Cys})$ \\
\hline rs373161821 & $159,755,405(+)$ & GTTAC(A/G)TAAAT & Missense & $\mathrm{V}(\mathrm{Val}) \Rightarrow \mathrm{I}(\mathrm{Ile})$ \\
\hline rs375163417 & $159,755,312(+)$ & GCAAC(A/G)CAACC & Missense & $\mathrm{T}(\mathrm{Thr}) \Rightarrow \mathrm{A}(\mathrm{Ala})$ \\
\hline rs375840138 & $159,755,421(+)$ & CAGTG(C/T)GGGGT & Missense & $\mathrm{A}(\mathrm{Ala}) \Rightarrow \mathrm{V}(\mathrm{Val})$ \\
\hline rs528166112 & $159,755,353(+)$ & GGTAA(A/T)AAGTC & Missense & $\mathrm{N}($ Asn $) \Rightarrow \mathrm{K}$ (Lys) \\
\hline rs532857576 & $159,748,230(+)$ & CGAGC(A/G)TTGCC & Missense & $\mathrm{V}(\mathrm{Val}) \Rightarrow \mathrm{I}(\mathrm{Ile})$ \\
\hline rs543667028 & $159,755,190(+)$ & AGCTT(C/T)TGAAC & Missense & $\mathrm{S}(\mathrm{Ser}) \Rightarrow \mathrm{F}(\mathrm{Phe})$ \\
\hline rs546830649 & $159,755,349(+)$ & GAATG(A/G)TAATA & Missense & $\mathrm{G}$ (Gly) $\Rightarrow \mathrm{D}$ (Asp) \\
\hline rs558627827 & $159,742,104(+)$ & ATGAA(A/G)CATAT & Missense & $\mathrm{A}(\mathrm{Ala}) \Rightarrow \mathrm{T}$ (Thr) \\
\hline rs560214098 & $159,748,326(+)$ & GCATC(A/G)TCTGC & Missense & $\mathrm{Q}(\mathrm{Gln}) \Rightarrow \mathrm{K}(\mathrm{Lys})$ \\
\hline rs563264867 & $159,755,400(+)$ & TAGTG(A/G)TTACG & Missense & $\mathrm{G}(\mathrm{Gly}) \Rightarrow \mathrm{D}(\mathrm{Asp})$ \\
\hline
\end{tabular}

SNP, single nucleotide polymorphism; WTAP, Wilms tumor 1 associated protein; Chr, chromosome.

65 somatic mutations of the human WTAP gene were identified in various types of cancer tissue (Table II).

Meta-analysis of the prognostic value of human WTAP gene expression in cancer tissues. A total of 17 out of 328 microarrays identified an association between WTAP gene expressions and cancer prognosis (bladder cancers, 1/7; blood cancers, 0/37; brain cancers, $1 / 23$; breast cancers, $5 / 110$; colorectal cancers, 3/48; esophagus cancers, $0 / 1$; eye cancers, $2 / 5$; head and neck cancers, 0/6; lung cancers, 4/56; ovarian cancers, $0 / 25$; prostate cancers, $0 / 1$; skin cancers, $0 / 6$; and soft tissue cancers, $1 / 3$ ), $\mathrm{P}<0.05$ (Table III) (28-38). In bladder, brain, eye and soft tissue cancers, reduced expression of the WTAP gene was associated with poor survival. However, an increased expression of the WTAP gene was associated with poor survival in lung cancer. Of the six breast cancer microarrays, reduced expression of the WTAP gene was associated with poor survival in two cases from the same database (GSE2990) and in the database GSE1456-GPL96, while increased expression of the WTAP gene was associated with poor survival in the GSE1456-GPL96 and GSE1456-GPL97 databases. Of the colorectal cancer microarrays, reduced expression of the WTAP gene was associated with poor survival in two cases (GSE17537 and GSE17538), while increased expression of the WTAP gene was associated with poor survival in the GSE14333 database.

\section{Discussion}

WT1 was first identified due to its essential role in the normal development of the human genitourinary system (1) and WTAP was identified as a protein that interacted with WT1 (3). A total of 44 complete WTAP genes were identified in the human, chimpanzee, gibbon, macaque, gorilla, orangutan, olive baboon, vervet monkey, marmoset, tarsier, bush baby, armadillo, sloth, squirrel, elephant, guinea pig, mouse, rat, pika, horse, microbat, ferret, dolphin, dog, pig, sheep, cow, alpaca, chicken, duck, turkey, flycatcher, zebra finch, Chinese softshell turtle, anole lizard, spotted gar, Amazon molly, platyfish, stickleback, tilapia, medaka, cave fish and zebrafish genomes. It was observed that WTAP genes were widely expressed in vertebrates, existing in fish, amphibians, birds and mammals. The phylogenetic tree revealed that the vertebrate WTAP proteins were clustered into the primate, rodent and teleost lineages. All vertebrate WTAPs are conserved according to the analysis of alignment and phylogenetic tree construction. Furthermore, the vertebrate WTAPs were under purifying selection. These results suggest that WTAP performs an essential physiological role in all vertebrates.

WTAP was predominantly expressed in bone marrow, whole blood, lymph node, brain, cerebellum, retina, spinal cord, heart, smooth muscle, skeletal muscle, small intestine, colon, adipocyte, kidney, liver, lung, pancreas, thyroid, salivary gland, adrenal gland, skin, ovary, uterus, placenta, prostate and testis. The expression pattern of WTAP appeared to be ubiquitous, which is indicative of a housekeeping role. By contrast, WT1 is expressed at low levels in only the spleen, heart, gonad and kidney (3). A total of 19 SNPs that cause missense mutations were identified in the human WTAP gene; however, it remains unclear whether these SNPs affect the physiological or pathological functions of WTAP. 


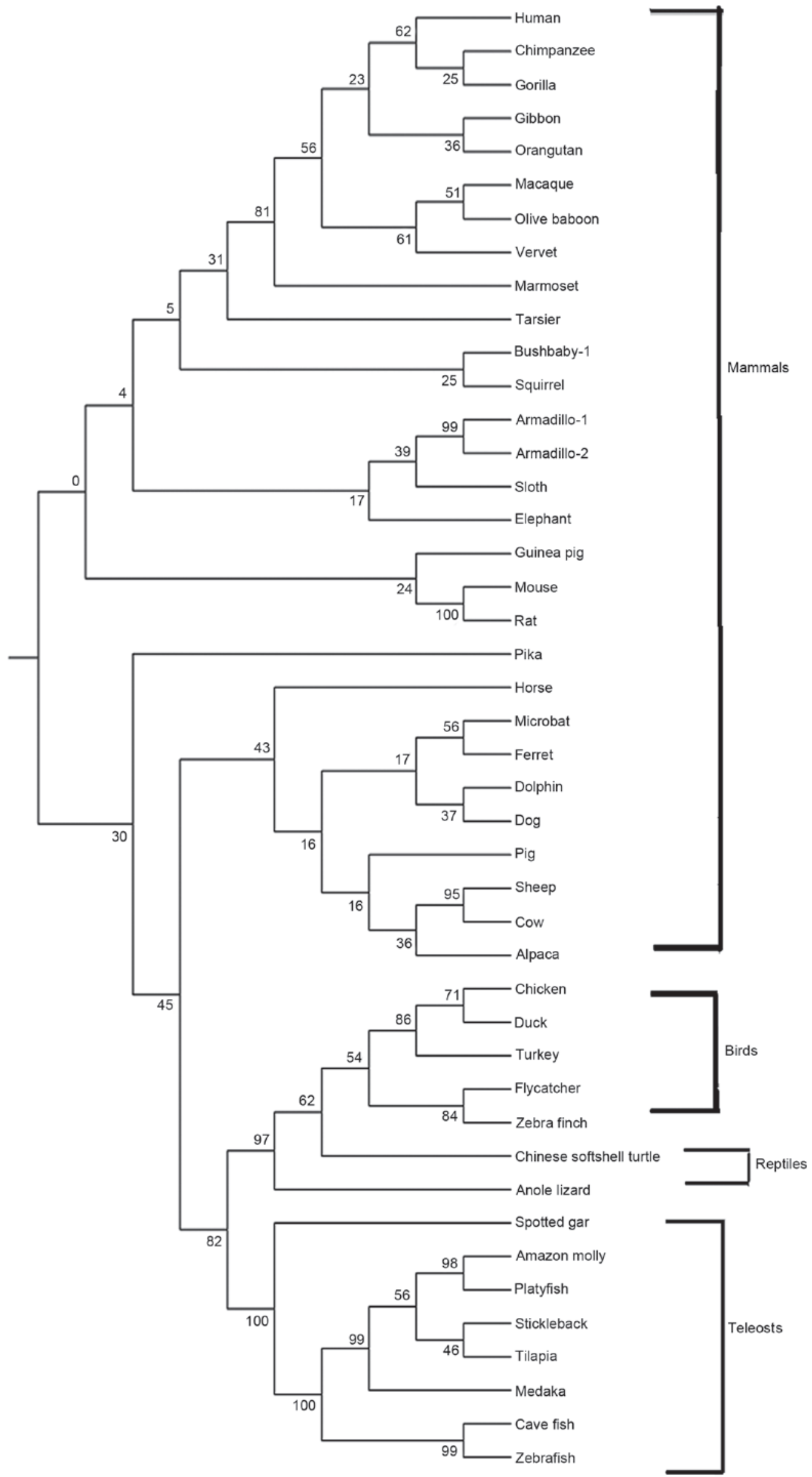

Figure 1. Phylogenetic tree of vertebrate WTAP. The phylogenetic tree of vertebrate WTAP was constructed using the maximum likelihood method. Vertebrate WTAP clustered into primate, rodent and teleost lineages. 
Table II. Somatic mutations of WTAP in cancer tissues.

\begin{tabular}{|c|c|c|c|c|c|}
\hline $\begin{array}{l}\text { Position } \\
\text { (AA) }\end{array}$ & $\begin{array}{l}\text { Mutation } \\
\text { (CDS) }\end{array}$ & $\begin{array}{c}\text { Mutation } \\
\text { (amino acid) }\end{array}$ & $\begin{array}{l}\text { Mutation ID } \\
\text { (COSM) }\end{array}$ & Count & $\begin{array}{l}\text { Mutation } \\
\text { type }\end{array}$ \\
\hline 12 & c. $34 \mathrm{C}>\mathrm{T}$ & $\mathrm{p} \cdot \mathrm{R} 12^{\mathrm{a}}$ & COSM207378 & 3 & Substitution-nonsense \\
\hline 30 & c. $90 \mathrm{G}>\mathrm{A}$ & p.W30 & COSM223136 & 1 & Substitution-nonsense \\
\hline 32 & c. $96 \mathrm{~A}>\mathrm{T}$ & p.Q32H & COSM3622455 & 1 & Substitution-missense \\
\hline 33 & c. $98 \mathrm{~A}>\mathrm{G}$ & p.Y33C & COSM4930374 & 1 & Substitution-missense \\
\hline 35 & c. $104 \mathrm{C}>\mathrm{T}$ & p.A35V & COSM4445039 & 1 & Substitution-missense \\
\hline 44 & c. $132 \mathrm{C}>\mathrm{A}$ & p.Y44 ${ }^{\mathrm{a}}$ & COSM450822 & 1 & Substitution-nonsense \\
\hline 51 & c. $152 \mathrm{~A}>\mathrm{C}$ & p.D51A & COSM450823 & 1 & Substitution-missense \\
\hline 54 & c. $161 \mathrm{G}>\mathrm{A}$ & p.G54D & COSM3860103 & 1 & Substitution-missense \\
\hline 66 & c. $198 \mathrm{G}>\mathrm{A}$ & p.Q66Q & COSM1075534 & 1 & Substitution-coding silent \\
\hline 71 & c. $211 \mathrm{C}>\mathrm{T}$ & p.R71C & COSM3860104 & 1 & Substitution-missense \\
\hline 79 & c. $235 \mathrm{C}>\mathrm{T}$ & p.R79a & COSM1441924 & 1 & Substitution-nonsense \\
\hline 79 & c. $236 \mathrm{G}>\mathrm{A}$ & p.R79Q & COSM450824 & 1 & Substitution-missense \\
\hline 86 & c. $256 \mathrm{G}>\mathrm{A}$ & p.E86K & COSM741338 & 1 & Substitution-missense \\
\hline 91 & c. $271 \mathrm{~A}>\mathrm{G}$ & p.T91A & COSM1496256 & 1 & Substitution-missense \\
\hline 95 & c. $283 \mathrm{C}>\mathrm{T}$ & p.Q95 & COSM1621161 & 2 & Substitution-nonsense \\
\hline 103 & c. $307 \mathrm{C}>\mathrm{T}$ & p.P103S & COSM1075535 & 1 & Substitution-missense \\
\hline 104 & c. $312 \mathrm{C}>\mathrm{T}$ & p.S104S & COSM1441925 & 1 & Substitution-coding silent \\
\hline 108 & c. $324 \mathrm{G}>\mathrm{C}$ & p.L108L & COSM1311778 & 1 & Substitution-coding silent \\
\hline 116 & c. $347 \mathrm{C}>\mathrm{T}$ & p.A116V & COSM1311779 & 1 & Substitution-missense \\
\hline 117 & c. $350 \mathrm{~T}>\mathrm{A}$ & p.I117N & COSM595210 & 1 & Substitution-missense \\
\hline 119 & c. $355 \mathrm{~T}>\mathrm{G}$ & p.L119V & COSM1075536 & 1 & Substitution-missense \\
\hline 135 & c. $405 \mathrm{G}>\mathrm{T}$ & p.L135L & COSM450825 & 1 & Substitution-coding silent \\
\hline 141 & c. $421 \mathrm{G}>\mathrm{A}$ & p.E141K & COSM4806762 & 1 & Substitution-missense \\
\hline 147 & c. $440 \mathrm{~T}>\mathrm{C}$ & p.F147S & COSM1075537 & 1 & Substitution-missense \\
\hline 148 & c. $443 \mathrm{C}>\mathrm{T}$ & p.T148M & COSM1232873 & 1 & Substitution-missense \\
\hline 150 & c. $448 \mathrm{G}>\mathrm{A}$ & p.D150N & COSM3023284 & 1 & Substitution-missense \\
\hline 150 & c. $448 \mathrm{G}>\mathrm{C}$ & p.D150H & COSM4828326 & 1 & Substitution-missense \\
\hline 154 & c. $461 \mathrm{G}>\mathrm{A}$ & p.G154E & COSM341987 & 2 & Substitution-missense \\
\hline 156 & c. $466 \mathrm{~A}>\mathrm{G}$ & p.K156E & COSM5003572 & 1 & Substitution-missense \\
\hline 156 & c. $467 \mathrm{~A}>\mathrm{G}$ & p.K156R & COSM420994 & 1 & Substitution-missense \\
\hline 157 & c. $470 \mathrm{~T}>\mathrm{C}$ & p.L157S & COSM1545449 & 1 & Substitution-missense \\
\hline 159 & c. $476 \mathrm{C}>\mathrm{A}$ & p.A159E & COSM248361 & 1 & Substitution-missense \\
\hline 159 & c. $476 \mathrm{C}>\mathrm{T}$ & p.A159V & COSM3023287 & 1 & Substitution-missense \\
\hline 162 & c. $485 \mathrm{G}>\mathrm{A}$ & p.R162Q & COSM1441926 & 1 & Substitution-missense \\
\hline 162 & c. $485 \mathrm{G}>\mathrm{C}$ & p.R162P & COSM1487425 & 1 & Substitution-missense \\
\hline 163 & c. $489 \mathrm{G}>\mathrm{A}$ & p.M163I & COSM483632 & 1 & Substitution-missense \\
\hline 163 & c.489_494delGCTTAT & p.M163_L164delML & COSM242271 & 1 & Deletion-in frame \\
\hline 164 & c. $491 \mathrm{~T}>\mathrm{C}$ & p.L164P & COSM1311780 & 1 & Substitution-missense \\
\hline 209 & c. $627 \mathrm{C}>\mathrm{A}$ & p.I209I & COSM3366370 & 1 & Substitution-coding silent \\
\hline 211 & c. $632 \mathrm{~T}>\mathrm{G}$ & p.L211R & COSM4880307 & 1 & Substitution-missense \\
\hline 212 & c. $635 \mathrm{~A}>\mathrm{C}$ & p.D212A & COSM595209 & 1 & Substitution-missense \\
\hline 226 & c. $676 \mathrm{C}>\mathrm{T}$ & p.Q226 ${ }^{\mathrm{a}}$ & COSM4741494 & 1 & Substitution-nonsense \\
\hline 231 & c. $693 \mathrm{G}>\mathrm{A}$ & p.E231E & COSM207380 & 1 & Substitution-coding silent \\
\hline 248 & c. $744 \mathrm{C}>\mathrm{T}$ & p.A248A & COSM1270542 & 1 & Substitution-coding silent \\
\hline 250 & c. $749 \mathrm{G}>\mathrm{C}$ & p.S250T & COSM395321 & 1 & Substitution-missense \\
\hline 255 & c. $763 \mathrm{~A}>\mathrm{G}$ & p.T255A & COSM4645558 & 1 & Substitution-missense \\
\hline 255 & c. $765 \mathrm{~A}>\mathrm{T}$ & p.T255T & COSM741337 & 1 & Substitution-coding silent \\
\hline 271 & c. $811 \mathrm{~A}>\mathrm{T}$ & p.S271C & COSM3023294 & 2 & Substitution-missense \\
\hline 305 & c. $913 \mathrm{~T}>\mathrm{C}$ & p.S305P & COSM3622456 & 1 & Substitution-missense \\
\hline 308 & c. $922 \mathrm{G}>\mathrm{T}$ & p.G308W & COSM1441927 & 1 & Substitution-missense \\
\hline 309 & c. $927 \mathrm{~T}>\mathrm{G}$ & p.N309K & COSM4160342 & 1 & Substitution-missense \\
\hline
\end{tabular}


Table II. Continued.

\begin{tabular}{|c|c|c|c|c|c|}
\hline $\begin{array}{l}\text { Position } \\
\text { (AA) }\end{array}$ & $\begin{array}{l}\text { Mutation } \\
\text { (CDS) }\end{array}$ & $\begin{array}{c}\text { Mutation } \\
\text { (Amino acid) }\end{array}$ & $\begin{array}{l}\text { Mutation ID } \\
\text { (COSM) }\end{array}$ & Count & $\begin{array}{l}\text { Mutation } \\
\text { type }\end{array}$ \\
\hline 314 & c. $941 \mathrm{C}>\mathrm{G}$ & p.S314C & COSM1645128 & 1 & Substitution-missense \\
\hline 334 & c. $1001 \mathrm{C}>\mathrm{T}$ & p.A334V & COSM3928204 & 2 & Substitution-missense \\
\hline 335 & c. $1003 \mathrm{G}>\mathrm{T}$ & p.G335W & COSM595208 & 1 & Substitution-missense \\
\hline 342 & c.1020_1021delCT & p.P342fs ${ }^{\mathrm{a}} 4$ & COSM3732402 & 1 & Deletion-frameshift \\
\hline 343 & c. $1029 \mathrm{G}>\mathrm{A}$ & p.T343T & COSM4741495 & 1 & Substitution-coding silent \\
\hline 353 & c. $1058 \mathrm{C}>\mathrm{G}$ & p.S353 & COSM1545448 & 1 & Substitution-nonsense \\
\hline 367 & c. $1099 \mathrm{G}>\mathrm{T}$ & p.A367S & COSM1075538 & 1 & Substitution-missense \\
\hline 368 & c. $1104 \mathrm{G}>\mathrm{C}$ & p.V368V & COSM4832802 & 1 & Substitution-coding silent \\
\hline 374 & c. $1120 \mathrm{C}>\mathrm{T}$ & p.R374 ${ }^{\mathrm{a}}$ & COSM4741496 & 1 & Substitution-nonsense \\
\hline 374 & c. $1121 \mathrm{G}>\mathrm{A}$ & p.R374Q & COSM1075539 & 1 & Substitution-missense \\
\hline 377 & c. $1130 \mathrm{G}>\mathrm{C}$ & p.G377A & COSM4980694 & 1 & Substitution-missense \\
\hline 384 & c. $1150 \mathrm{G}>\mathrm{A}$ & p.G384S & COSM4637994 & 1 & Substitution-missense \\
\hline 391 & c. $1173 \mathrm{~A}>\mathrm{G}$ & p.V391V & COSM3023307 & 1 & Substitution-coding silent \\
\hline 393 & c. $1178 \mathrm{G}>\mathrm{T}$ & p.G393V & COSM595207 & 1 & Substitution-missense \\
\hline
\end{tabular}

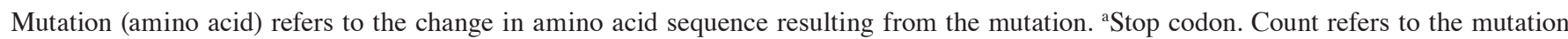
number identified in the database. WTAP, wilms tumor 1 associated protein; AA, amino acid; CDS, coding DNA sequence; COSM, catalogue of somatic mutations.

WTAP and WT1 partially co-localize with splicing factors, and are distributed together in the nucleoplasm and in nuclear speckles (3). It has been demonstrated in numerous tumors that WT1 is a tumor suppressor, exerting effects including inhibiting cell proliferation and enhancing apoptosis (39-42). However, WTAP is an oncogene, which is overexpressed in cholangiocarcinoma (11), glioblastoma (12) and acute myeloid leukemia (13). In the present study, it was demonstrated that WTAP was expressed in bladder, blood, brain, breast, colorectal, esophagus, eye, head and neck, lung, ovarian, prostate, skin and soft tissue cancers. Of a total of 328 microarrays, 17 revealed an association between microarray WTAP expression and cancer prognosis (bladder cancers, 1; brain cancers, 1; breast cancers, 6; colorectal cancers, 3; eye cancers, 2; lung cancers, 4 ; and soft tissue cancers, 1 ). The majority of microarrays did not reveal an association between microarray WTAP expression and cancer prognosis. This may be due to a lack of WTAP expression information in the database. Notably, WTAP was not involved in all tumor types. In addition, it is notable that the association between WTAP expression and prognosis varied between the different cancer types, and even in identical cancers from separate databases. This suggests that the function of WTAP in these tumors may not be solely as an oncogene, but may be multidimensional (11-13). The differing WTAP expression in various tumors may be due to the distinct oncogenes or tumor suppressors stabilized by WTAP in particular tumors $(9,10)$.

Furthermore, 65 somatic mutations of WTAP were identified in cancer tissues. The effects of these mutations on tumor formation remain to be elucidated and require future investigation. The results of the present study suggest that WTAP has a comprehensive and complex role in tumor formation. STAT1, FOXO1, IRF1, glucocorticoid receptor and
PPAR $\gamma$ transcription factor binding sites were identified in the upstream (promoter) region of the WTAP gene. STAT1 is a cytoplasmic protein, which functions as a signal messenger and transcription factor in cellular responses to cytokines and growth factors (43). It exhibits anti-tumor functions via control of the immune system and promotion of tumor immune surveillance (44-46). FOXO1 is an important transcriptional regulator of cell proliferation and is considered to be essential for tumor growth and progression (47). Deregulation of FOXO1 promotes cell proliferation and tumorigenesis, and has thus become a primary target of tumorigenesis prevention $(48,49)$. IRF1 is involved in the regulation of interferon $\alpha$ and $\beta$ transcription, and it has been demonstrated that IRF1 gene deletion or rearrangement correlates with the development of human cancers $(50,51)$. The glucocorticoid receptor is a member of the nuclear receptor family, which acts as a ligand-dependent transcription factor to regulate gene expression. In addition, the estrogen and androgen receptors are members of the nuclear receptor family. In breast cancer, the estrogen receptor drives cell growth, proliferation and metastasis, and the androgen receptor has a similar role in prostate cancer $(52,53)$. These tumor-associated transcriptional factors may affect the expression of WTAP and contribute to tumor formation (12-14).

In conclusion, 44 complete WTAP genes were identified in vertebrate genomes. The vertebrate WTAP proteins clustered into the primate, rodent and teleost lineages. The association between WTAP gene expression and prognosis varied in distinct cancers, and even in identical cancers from separate microarray databases. Furthermore, a total of 65 somatic mutations were identified in the human WTAP gene from cancer tissue samples. The results of the present study suggest that the function of WTAP in tumor formation may be multidimensional. 


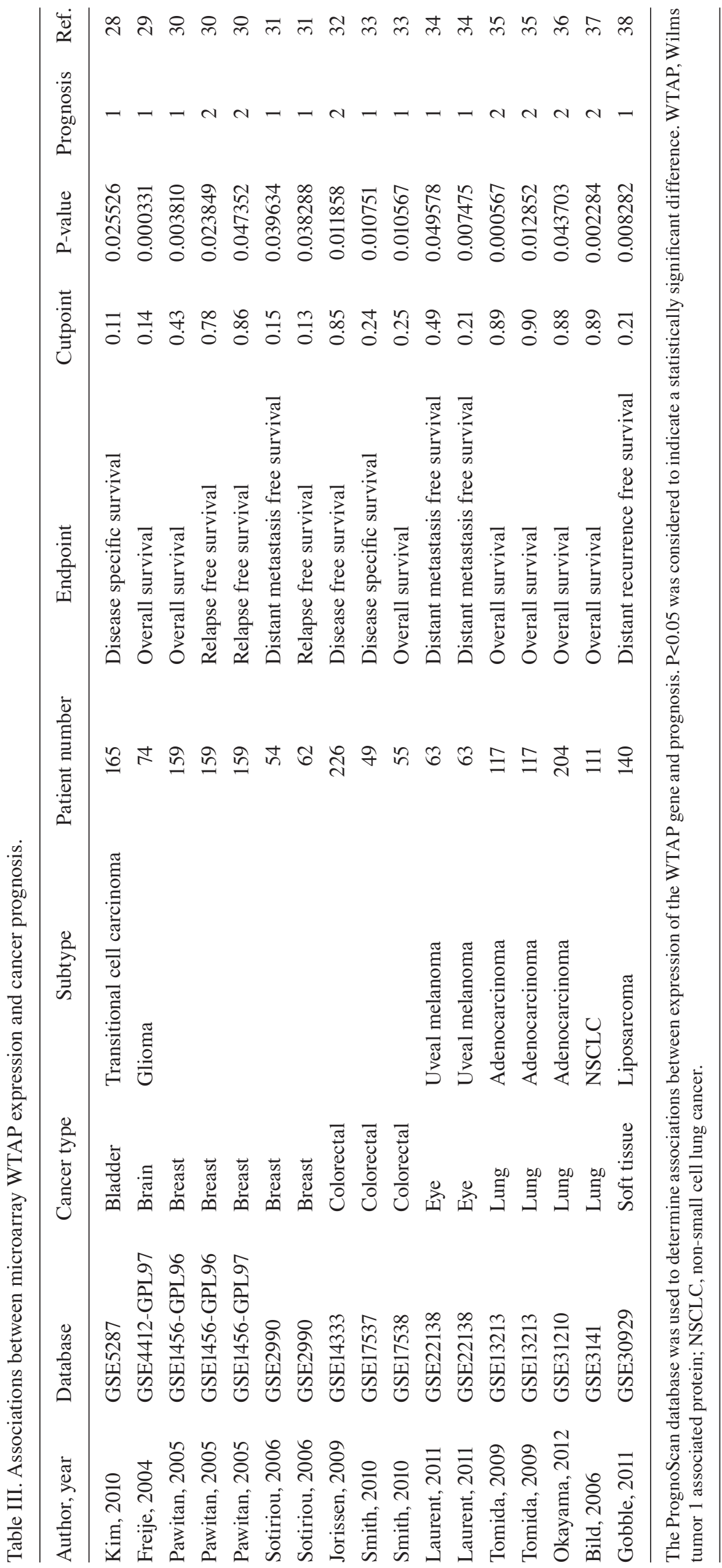




\section{Acknowledgements}

The present study was supported by Anhui Science and Technology Research Projects (grant no. 130zc04065), the National Natural Science Foundation of China (grant nos. 81372828 and 810001329), and the Priority Academic Program Development of Jiangsu Higher Education Institutions.

\section{References}

1. Kreidberg JA, Sariola H, Loring JM, Maeda M, Pelletier J, Housman D and Jaenisch R: WT-1 is required for early kidney development. Cell 74: 679-691, 1993.

2. Kim MK, McGarry TJ, O Broin P, Flatow JM, Golden AA and Licht JD: An integrated genome screen identifies the Wnt signaling pathway as a major target of WT1. Proc Natl Acad Sci USA 106: 11154-11159, 2009.

3. Little NA, Hastie ND and Davies RC: Identification of WTAP, a novel Wilms' tumour 1-associating protein. Hum Mol Genet 9: 2231-2239, 2000.

4. Granadino B, Penalva LO and Sánchez L: The gene $\mathrm{fl}(2) \mathrm{d}$ is needed for the sex-specific splicing of transformer pre-mRNA but not for double-sex pre-mRNA in Drosophila melanogaster. Mol Gen Genet 253: 26-31, 1996.

5. Penalva LO, Ruiz MF, Ortega A, Granadino B, Vicente L, Segarra C, Valcárcel J and Sánchez L: The drosophila fl(2) $\mathrm{d}$ gene, required for female-specific splicing of Sxl and tra pre-mRNAs, encodes a novel nuclear protein with a HQ-rich domain. Genetics 155: 129-139, 2000.

6. Horiuchi K, Umetani M, Minami T, Okayama H, Takada S, Yamamoto M, Aburatani H, Reid PC, Housman DE, Hamakubo T and Kodama T: Wilms' tumor 1-associating protein regulates G2/M transition through stabilization of cyclin A2 mRNA. Proc Natl Acad Sci USA 103: 17278-17283, 2006.

7. Naruse C, Fukusumi Y, Kakiuchi D and Asano M: A novel gene trapping for identifying genes expressed under the control of specific transcription factors. Biochem Biophys Res Commun 361: 109-115, 2007.

8. Horiuchi K, Kawamura T, Iwanari H, Ohashi R, Naito M, Kodama T and Hamakubo T: Identification of Wilms' tumor 1 -associating protein complex and its role in alternative splicing and the cell cycle. J Biol Chem 288: 33292-33302, 2013.

9. Schwartz S, Mumbach MR, Jovanovic M, Wang T, Maciag K, Bushkin GG, Mertins P, Ter-Ovanesyan D, Habib N, Cacchiarelli $\mathrm{D}$, et al: Perturbation of $\mathrm{m} 6 \mathrm{~A}$ writers reveals two distinct classes of mRNA methylation at internal and 5' sites. Cell Rep 8: 284-296, 2014.

10. Ping XL, Sun BF, Wang L, Xiao W, Yang X, Wang WJ, Adhikari S, Shi Y, Lv Y, Chen YS, et al: Mammalian WTAP is a regulatory subunit of the RNA N6-methyladenosine methyltransferase. Cell Res 24: 177-189, 2014.

11. Jo HJ, Shim HE, Han ME, Kim HJ, Kim KS, Baek S, Choi KU, Hur GY and Oh SO: WTAP regulates migration and invasion of cholangiocarcinoma cells. J Gastroenterol 48: 1271-1282, 2013.

12. Jin DI, Lee SW, Han ME, Kim HJ, Seo SA, Hur GY, Jung S, Kim BS and Oh SO: Expression and roles of Wilms' tumor 1-associating protein in glioblastoma. Cancer Sci 103: 2102-2109, 2012.

13. Bansal H, Yihua Q, Iyer SP, Ganapathy S, Proia DA, Penalva LO, Uren PJ, Suresh U, Carew JS, Karnad AB, et al: WTAP is a novel oncogenic protein in acute myeloid leukemia. Leukemia 28: 1171-1174, 2014.

14. Zhang J, Tsoi H, Li X, Wang H, Gao J, Wang K, Go MY, $\mathrm{Ng} \mathrm{SC}$, Chan FK, Sung JJ and Yu J: Carbonic anhydrase IV inhibits colon cancer development by inhibiting the Wnt signalling pathway through targeting the WTAP-WT1-TBL1 axis. Gut: pii: gutjnl-2014-308614, 2015 (Epub ahead of print).

15. Ding Z, Yang HW, Xia TS, Wang B and Ding Q: Integrative genomic analyses of the RNA-binding protein, RNPC1, and its potential role in cancer prediction. Int J Mol Med 36: 473-484, 2015.

16. Wang B, Xu W, Tan M, Xiao Y, Yang H and Xia TS: Integrative genomic analyses of a novel cytokine, interleukin-34 and its potential role in cancer prediction. Int J Mol Med 35: 92-102, 2015 .
17. Yang L, Luo Y and Wei J: Integrative genomic analyses on Ikaros and its expression related to solid cancer prognosis. Oncol Rep 24: 571-577, 2010.

18. Yang L, Luo Y, Wei J and He S: Integrative genomic analyses on IL28RA, the common receptor of interferon-lambda1, -lambda2 and -lambda3. Int J Mol Med 25: 807-812. 2010.

19. Yang L, Wei J and He S: Integrative genomic analyses on interferon-lambdas and their roles in cancer prediction. Int J Mol Med 25: 299-304, 2010.

20. Wang M, Wei X, Shi L, Chen B, Zhao G and Yang H: Integrative genomic analyses of the histamine $\mathrm{H} 1$ receptor and its role in cancer prediction. Int J Mol Med 33: 1019-1026, 2014.

21. Wang B, Chen K, Xu W, Chen D, Tang W and Xia TS: Integrative genomic analyses of secreted protein acidic and rich in cysteine and its role in cancer prediction. Mol Med Rep 10: 1461-1468, 2014.

22. Kumar S, Nei M, Dudley J and Tamura K: MEGA: A biologist-centric software for evolutionary analysis of DNA and protein sequences. Brief Bioinform 9: 299-306, 2008.

23. Yang Z: PAML: A program package for phylogenetic analysis by maximum likelihood. Comput Appl Biosci 13: 555-556, 1997.

24. Forbes SA, Bindal N, Bamford S, Cole C, Kok CY, Beare D, Jia M, Shepherd R, Leung K, Menzies A, et al: COSMIC: Mining complete cancer genomes in the catalogue of somatic mutations in cancer. Nucleic Acids Res 39 (Database issue): D945-D950, 2011.

25. Chalifa-Caspi V, Yanai I, Ophir R, Rosen N, Shmoish M, Benjamin-Rodrig H, Shklar M, Stein TI, Shmueli O, Safran M and Lancet D: GeneAnnot: Comprehensive two-way linking between oligonucleotide array probesets and GeneCards genes. Bioinformatics 20: 1457-1458, 2004.

26. Parkinson H, Sarkans U, Shojatalab M, Abeygunawardena N, Contrino S, Coulson R, Farne A, Lara GG, Holloway E, Kapushesky M, et al: ArrayExpress-a public repository for microarray gene expression data at the EBI. Nucleic Acids Res 33 (Database issue): D553-D555, 2005.

27. Mizuno H, Kitada K, Nakai K and Sarai A: PrognoScan: A new database for meta-analysis of the prognostic value of genes. BMC Med Genomics 2: 18, 2009.

28. Kim WJ, Kim EJ, Kim SK, Kim YJ, Ha YS, Jeong P, Kim MJ, Yun SJ, Lee KM, Moon SK, et al: Predictive value of progression-related gene classifier in primary non-muscle invasive bladder cancer. Mol Cancer 9: 3, 2010.

29. Freije WA, Castro-Vargas FE, Fang Z, Horvath S, Cloughesy T, Liau LM, Mischel PS and Nelson SF: Gene expression profiling of gliomas strongly predicts survival. Cancer Res 64: 6503-6510, 2004.

30. Pawitan Y, Bjöhle J, Amler L, Borg AL, Egyhazi S, Hall P, Han X, Holmberg L, Huang F, Klaar S, et al: Gene expression profiling spares early breast cancer patients from adjuvant therapy: Derived and validated in two population-based cohorts. Breast Cancer Res 7: R953-R964, 2005.

31. Sotiriou C, Wirapati P, Loi S, Harris A, Fox S, Smeds J, Nordgren H, Farmer P, Praz V, Haibe-Kains B, et al: Gene expression profiling in breast cancer: Understanding the molecular basis of histologic grade to improve prognosis. J Natl Cancer Inst 98: 262-272, 2006.

32. Jorissen RN, Gibbs P, Christie M, Prakash S, Lipton L, Desai J, Kerr D, Aaltonen LA, Arango D, Kruhøffer M, et al: Metastasis-associated gene expression changes: Predict poor outcomes in patients with dukes stage $\mathrm{B}$ and $\mathrm{C}$ colorectal cancer. Clin Cancer Res 15: 7642-7651, 2009.

33. Smith JJ, Deane NG, Wu F, Merchant NB, Zhang B, Jiang A, Lu P, Johnson JC, Schmidt C, Bailey CE, et al: Experimentally derived metastasis gene expression profile predicts recurrence and death in patients with colon cancer. Gastroenterology 138: 958-968, 2010.

34. Laurent C, Valet F, Planque N, Silveri L, Maacha S, Anezo O, Hupe P, Plancher C, Reyes C, Albaud B, et al: High PTP4A3 phosphatase expression correlates with metastatic risk in uveal melanoma patients. Cancer Res 71: 666-674, 2011.

35. Tomida S, Takeuchi T, Shimada Y, Arima C, Matsuo K, Mitsudomi T, Yatabe Y and Takahashi T: Relapse-related molecular signature in lung adenocarcinomas identifies patients with dismal prognosis. J Clin Oncol 27: 2793-2799, 2009.

36. Okayama H, Kohno T, Ishii Y, Shimada Y, Shiraishi K, Iwakawa R, Furuta K, Tsuta K, Shibata T, Yamamoto S, et al: Identification of genes upregulated in ALK-positive and EGFR/KRAS/ALK-negative lung adenocarcinomas. Cancer Res 72: 100-111, 2012. 
37. Bild AH, Yao G, Chang JT, Wang Q, Potti A, Chasse D, Joshi MB Harpole D, Lancaster JM, Berchuck A, et al: Oncogenic pathway signatures in human cancers as a guide to targeted therapies. Nature 439: 353-357, 2006.

38. Gobble RM, Qin LX, Brill ER, Angeles CV, Ugras S, O'Connor RB, Moraco NH, Decarolis PL, Antonescu C and Singer S: Expression profiling of liposarcoma yields a multigene predictor of patient outcome and identifies genes that contribute to liposarcomagenesis. Cancer Res 71: 2697-2705, 2011

39. Li Y, Wang J, Li X, Jia Y, Huai L, He K, Yu P, Wang M, Xing H, Rao Q, et al: Role of the Wilms' tumor 1 gene in the aberrant biological behavior of leukemic cells and the related mechanisms. Oncol Rep 32: 2680-2686, 2014.

40. Lee SY, Choe YJ, Park JY, Lee SS, Kim YH, Shin SJ, Chung YJ and Kim HS: Wilms' tumor gene 1 enhances nutlin-3-induced apoptosis. Oncol Rep 31: 131-136, 2014.

41. Liu Y and Liu S: Berberine inhibits Wilms' tumor cell progression through upregulation of Wilms' tumor gene on the $\mathrm{X}$ chromosome. Mol Med Rep 8: 1537-1541, 2013.

42. Li M, Cai MY, Lu JB, Hou JH, Wu QL and Luo RZ: Clinicopathological investigation of four cases of desmoplastic small round cell tumor. Oncol Lett 4: 423-428, 2012.

43. Ding Y, Yang M, She S, Min H, Xv X, Ran X, Wu Y, Wang W, Wang L, Yi L, et al: iTRAQ-based quantitative proteomic analysis of cervical cancer. Int J Oncol 46: 1748-1758, 2015.

44. Kaewpiboon C, Srisuttee R, Malilas W, Moon J, Oh S, Jeong HG, Johnston RN, Assavalapsakul W and Chung YH: Upregulation of Stat1-HDAC4 confers resistance to etoposide through enhanced multidrug resistance 1 expression in human A549 lung cancer cells. Mol Med Rep 11: 2315-2321, 2015.
45. Chen S, Li C, Wu B, Zhang C, Liu C, Lin X, Wu X, Sun L, Liu C, Chen B, et al: Identification of differentially expressed genes and their subpathways in recurrent versus primary bone giant cell tumors. Int J Oncol 45: 1133-1142, 2014.

46. Li W, Wei Q and Liang J: Phosphorylated signal transducer and activator of transcription 1 is a potential predictor of interferon response in patients with advanced renal cell carcinoma. Mol Med Rep 9: 1929-1934, 2014.

47. Zhao Z, Li C, Xi H, Gao Y and Xu D: Curcumin induces apoptosis in pancreatic cancer cells through the induction of forkhead box O1 and inhibition of the PI3K/Akt pathway. Mol Med Rep 12: 5415-5422, 2015

48. Gao F and Wang W: MicroRNA-96 promotes the proliferation of colorectal cancer cells and targets tumor protein p53 inducible nuclear protein 1 , forkhead box protein $\mathrm{O} 1$ (FOXO1) and FOXO3a. Mol Med Rep 11: 1200-1266, 2015.

49. Zhu H: Targeting forkhead box transcription factors FOXM1 and FOXO in leukemia (Review). Oncol Rep 32: 1327-1334, 2014

50. Xu Y, Wang W, Gou A, Li H, Tian Y, Yao M and Yang R: Effects of suppressor of cytokine signaling 1 silencing on human melanoma cell proliferation and interferon- $\gamma$ sensitivity. Mol Med Rep 11: 583-588, 2015.

51. Chen FF, Jiang G, Xu K and Zheng JN: Function and mechanism by which interferonregulatory factor- 1 inhibits oncogenesis. Oncol Lett 5: 417-423, 2013.

52. Pufall MA: Glucocorticoids and Cancer. Adv Exp Med Biol 872: 315-333, 2015.

53. Volden PA and Conzen SD: The influence of glucocorticoid signaling on tumor progression. Brain Behav Immun 30 (Suppl): S26-S31, 2013 